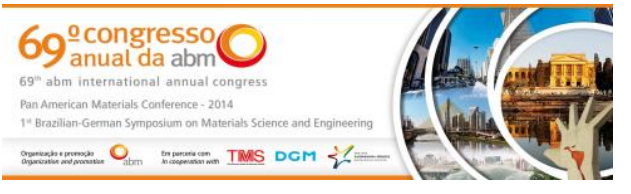

Tema: Metalurgia Física e Comportamento de Materiais em Temperaturas Elevadas

\title{
AVALIAÇÃO DO COMPORTAMENTO MECÂNICO DE UM AÇO IF ENTRE AS CADEIRAS DE UM LAMINADOR A FRIO*
}

\section{Resumo}

Bruna Silva de Almeida ${ }^{1}$

Gláucio Soares da Fonseca²

Tradicionalmente propriedades mecânicas tais como: Limite de escoamento e dureza em processos de laminação a frio são avaliadas antes e após o processo devido a dificuldade de obter estes valores após cada cadeira de laminação. Atualmente são empregadas simulações numéricas, onde inúmeros modelos usam valores de tensões antes e após laminação e obtém-se uma predição destes valores entre cadeiras, normalmente utilizando aproximações ou dados conseguidos em algum laminador piloto. A finalidade deste trabalho foi estudar uma bobina processada de um aço IF, em escala industrial, num laminador de tiras a frio de cinco cadeiras avaliando algumas propriedades mecânicas e correlacionando os aspectos microestruturais das amostras retiradas entre as cadeiras deste laminador. Para o estudo da evolução das propriedades mecânicas do início ao final do processo, foram preparadas amostras para os ensaios mecânicos e para análise das mudanças microestruturais foram preparadas amostras por técnicas de metalografia. O resultado apresentado após estas avaliações mostram o comportamento mecânico diferenciado após cada redução.

Palavras-chave: Laminação; Limite de escoamento; Aço IF.

\section{EVALUATION OF MECHANICAL BEHAVIOUR OF AN IFSTEEL BETWEEN THE STAND OF A COLD ROLLING MILL}

\section{Abstract}

Traditionally, mechanical properties such as yield strength and hardness in cold rolling processes are evaluated before and after the procedure because of the difficulty of obtaining these values after each rolling stand. Currently, numerical simulations are employed, where numerous models use stress values before and after the rolling process and a prediction of these values between stands is made, usually achieved using approximations or data from some pilot mill. The purpose of this study was a coil of an IF steel processed on an industrial scale, a cold strip mill of five stands evaluating some mechanical properties and correlating the microstructure of the samples taken between the stands of this laminator. To study the evolution of mechanical properties from start to end of the process, samples for mechanical testing were prepared and for the analysis of microstructural changes, the samples were prepared by metallographic techniques. The result presented after these evaluations show the unique mechanical behavior after each reduction.

Keywords: Lamination; Yield strength; IF Steel.

1 Graduanda em Engenharia Metalúrgica, EEIMVR/UFF, Estagiária Nível Superior, GRF - LTF\#3, CSN, Volta Redonda, RJ, Brasil.

2 Engenheiro Químico, Doutor em Engenharia Metalúrgica, Programa de Pós-graduação em Engenharia Metalúrgica, Departamento de Engenharia Mecânica, EEIMVR, UFF, Volta Redonda, RJ, Brasil.

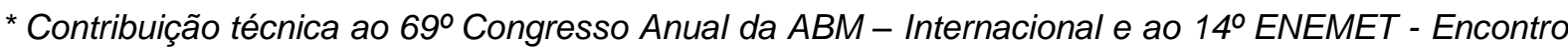
Nacional de Estudantes de Engenharia Metalúrgica, de Materiais e de Minas,21 a 25 de julho de 2014, São Paulo, SP, Brasil.
} 


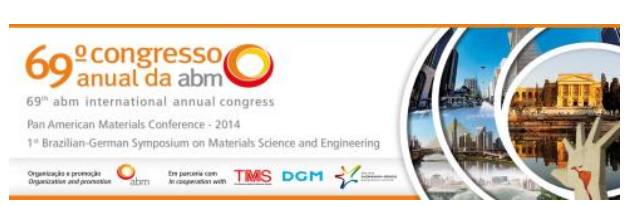

\section{INTRODUÇÃO}

A laminação a frio de produtos planos é um dos processos de conformação mais utilizados industrialmente sendo versátil, de alta produção e baixo custo [1] que visa reduzir a espessura do material laminado a quente e decapado. As reduções são limitadas ao efeito do endurecimento a frio do material que nada mais é que o fenômeno do encruamento. O processo proporciona um melhor acabamento superficial, as dimensões são mais precisas comparadas a laminação a quente e é nítido o aumento das propriedades mecânicas como limite de escoamento (LE), resistência à tração (LRT) e dureza ao custo da perda da ductilidade do material como mostra a figura 1.

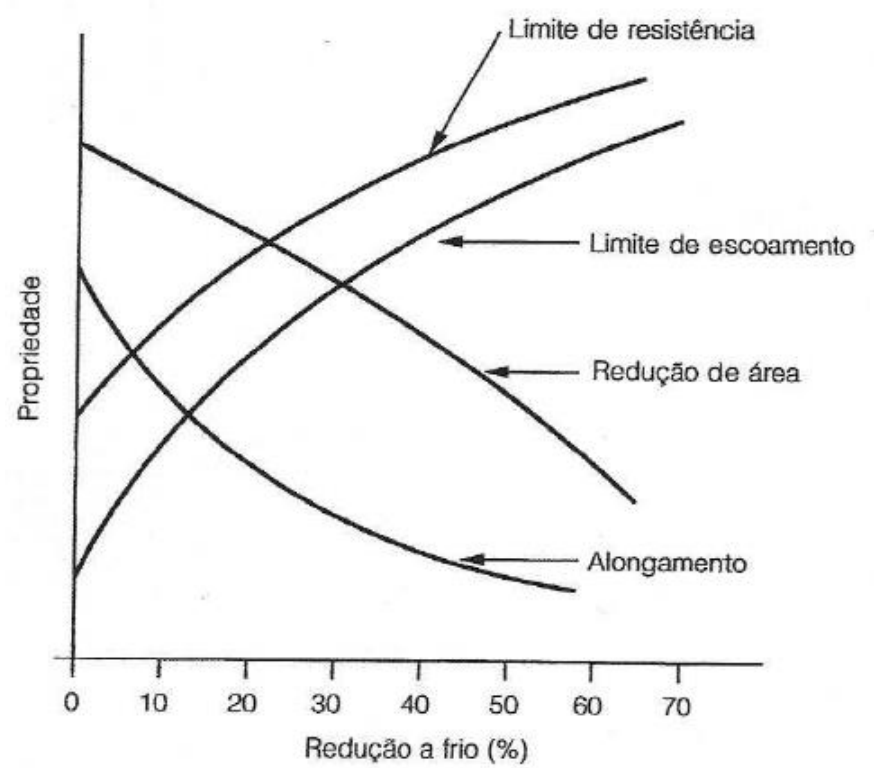

Figura 1. Variação típica de propriedades mecânicas de metais deformados a frio [2].

A deformação na laminação a frio ocorre no campo plástico, entre o limite de escoamento do material e o limite de resistência à tração, numa região de segurança como ilustra a figura 2, mantendo a largura e o volume constantes da bobina full hard $(\mathrm{BFH})[3]$.

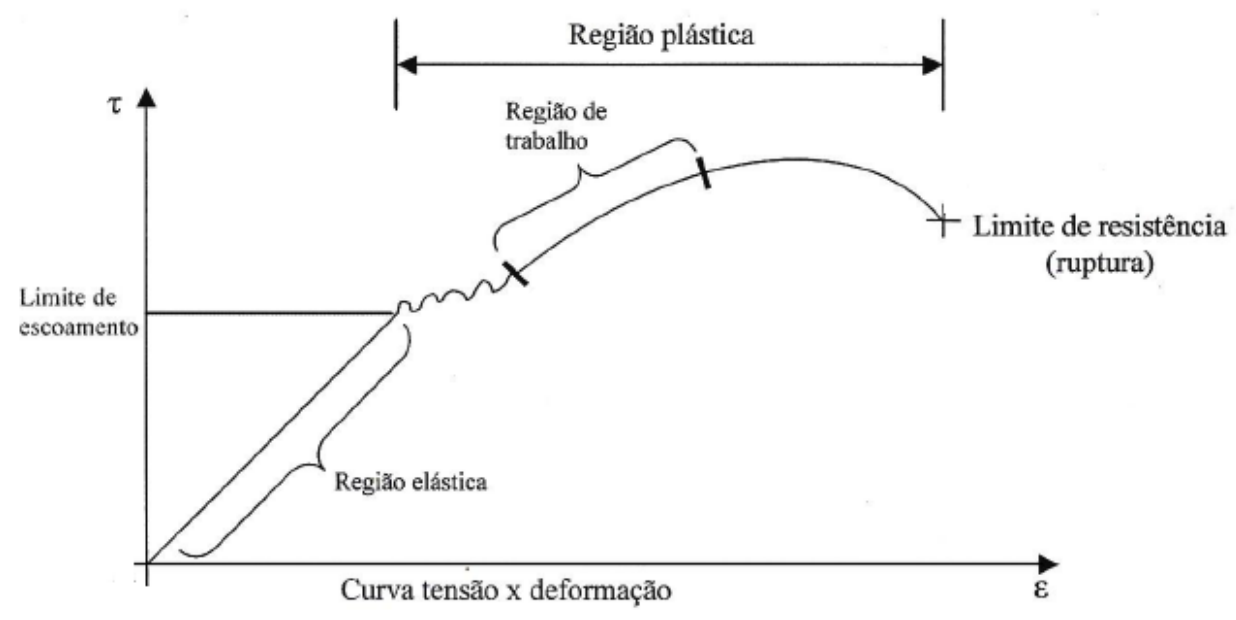

Figura 2. Representação da região de conformação na laminação a frio [3].

\footnotetext{
* Contribuição técnica ao $69^{\circ}$ Congresso Anual da ABM - Internacional e ao 14ํㅡㄹ ENEMET - Encontro Nacional de Estudantes de Engenharia Metalúrgica, de Materiais e de Minas,21 a 25 de julho de 2014, São Paulo, SP, Brasil.
} 
A escolha do aço IF (Interstitial Free, ou livre de intersticiais)no presente trabalho se justifica em ser hoje um dos aços mais utilizados na conformação de chapas para indústria automobilística entre outros segmentos, por oferecer excelentes propriedades para estampabilidade de componentes devido aos elevados valores dos coeficientes de anisotropia normal e de encruamento [4]. Os aços IF são obtidos a partir da redução de teores de $\mathrm{C}$ e $\mathrm{N}$ em solução sólida e da adição de elementos estabilizadores, como $\mathrm{Ti}$ e $\mathrm{Nb}$, capazes de formar carbonetos e nitretos. Além do fato de ser o material com as maiores taxas de redução a frio por se tratar de um material macio de baixo limite de escoamento e alto alongamento percentual [5].

O trabalho a frio é um importante processo de aumento de resistência mecânica do material como consequência ocorre o encruamento que é o endurecimento do material por deformação plástica. Em aços a deformação plástica muitas vezes envolve o movimento de discordâncias que fazem com que elas interajam entre si diretamente e com outros defeitos podendo se multiplicar [6]. Como características microestruturais podemos dizer que os grãos mudam sua forma e orientação seguindo preferencialmente o sentido de deformação, a área de contorno de grão por unidade de volume aumenta e a quantidade de defeitos de pontuais e discordâncias por unidade de volume aumenta [7]. A deformação plástica é inerentemente heterogênea, ou seja, varia de grão para grão e mesmo em um único grão [8].

As bandas de deformação são uma conseqüência inevitável da deformação de policristais e são facilmente identificadas ao microscópio ótico, este termo é usado para descrever um volume de orientação aproximadamente constante, que é significativamente diferente da orientação presente em outro ponto no mesmo grão, mas não chega a criar um contorno [9]. A diferença de orientação dentro do grão ocorre quando partes dele passaram por rotações em sentidos opostos durante a deformação plástica pelos diferentes sistemas de deslizamento.

Uma característica importante capaz de fornecer a medida da habilidade e ou capacidade do material distribuir uniformemente a deformação no estudo de aços destinados à estampagem como os aços IFs é o coeficiente de encruamento " $n$ " descrita na equação de Hollomon (1).

$$
\sigma=K \varepsilon^{n}(1)
$$

Esta equação é uma boa representação da curva $\sigma \times \varepsilon$ real, já que as tensões reais são maiores que as de engenharia que obtemos normalmente em ensaios de tração, e as deformações reais são menores. A equação de Hollomon só se aplica em aços e na zona plástica do gráfico $\sigma \times \varepsilon$ entre o limite de escoamento e o limite de resistência à tração. Quanto maior for o valor de $n$ mais inclinada será curva real e mais uniforme a distribuição das deformações na presença de variações de tensões [10].

A lei de Hooke é válida no regime elástico na parte linear do gráfico $\sigma \times \varepsilon$ de engenharia sendo descrita pela equação 2 , onde o $\mathrm{E}$ é o módulo de elasticidade ou de Young. Em aços o valor mais comum é de 200 a $210 \mathrm{GPa}$. Esta grandeza expressa à medida da rigidez assim quanto maior seu valor menor será a deformação elástica e mais rígido será o material [10].

$$
\sigma=E \varepsilon(2)
$$

Este trabalho buscou apresentar parâmetros importantes em processos de conformação mecânica como limite de escoamento, limite de resistência a tração e dureza de amostras retiradas em escala industrial de uma bobina de aço IF, no

\footnotetext{
* Contribuição técnica ao $69^{\circ}$ Congresso Anual da ABM - Internacional e ao 14ํㅡㄹ ENEMET - Encontro Nacional de Estudantes de Engenharia Metalúrgica, de Materiais e de Minas,21 a 25 de julho de 2014, São Paulo, SP, Brasil.
} 


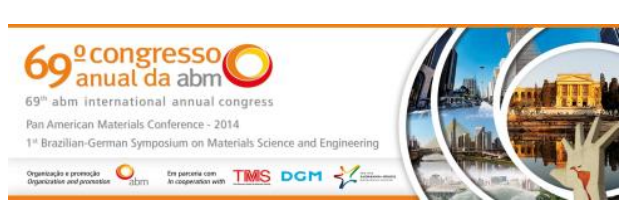

inicio, ao final e entre as sucessivas cadeiras do laminador de tiras a frio 3 da Companhia Siderúrgica Nacional. Além de analisar a microestrutura do material encruando gradativamente. A motivação para realizar este estudo é devido a grande dificuldade em obter tanto na literatura e ou em escala piloto valores intermediários de propriedades mecânicas no decorrer da laminação a frio.

\section{MATERIAIS E MÉTODOS}

As amostras foram obtidas de uma bobina de aço IF com dimensões de 3,75 mm de espessura inicial, espessura final de 0,76 e largura de $1291 \mathrm{~mm}$. A composição química está especificada na tabela 1.

Tabela 1. Composição química da amostra em \% de peso

\begin{tabular}{cccccc}
\hline $\mathrm{C}$ (máx) & Mn (máx) & $\mathrm{Si}(\mathrm{máx})$ & $\mathrm{Ti}(\operatorname{máx})$ & $\mathrm{P}$ (máx) & $\mathrm{S}$ (máx) \\
\hline 0,0034 & 0,16 & 0,03 & 0,07 & 0,015 & 0,012 \\
\hline
\end{tabular}

As amostras foram retiradas de uma bobina processada em escala industrial, onde o laminador foi parado durante o processo de laminação garantindo que o material estivesse ainda sob tensão, em seguida foi desligado o sistema de refrigeração para que pudesse ser feita a localização da posição da tira onde seriam cortadas as amostras identificando o ponto de entrada, entre uma cadeira e outra e na saída do laminador. A tabela 2 apresenta a identificação das amostras utilizada neste trabalho bem como a posição de amostragem de cada uma

Tabela 2. Identificação das amostras

\begin{tabular}{|c|c|}
\hline POSIÇÃO DA AMOSTRA & IDENTIFICAÇÃC \\
\hline $\begin{array}{l}\text { ENTRADA DO } \\
\text { LAMINADOR }\end{array}$ & ENTRADA \\
\hline APÓS 1a CADEIRA & 1 \\
\hline APÓS 2a CADEIRA & 2 \\
\hline APÓS 3aㅡ CADEIRA & 3 \\
\hline APÓS 4a CADEIRA & 4 \\
\hline SAÍDA DO LAMINADOR & SAÍDA \\
\hline
\end{tabular}

\subsection{Ensaio de Tração}

Foram realizados ensaios de tração em duas orientações (no sentido de laminaçãoDL e a $90^{\circ}$ da direção de laminação- DT) a fim de ter uma quantidade maior de dados e analisar as variações dos resultados de propriedades mecânicas em diferentes direções. Para realização dos ensaios foram confeccionados12 corpos de prova (CP) base $50 \mathrm{~mm}$ sendo 6CP's na DT e 6 CP's na DL, a máquina utilizada no ensaio é do tipo Instron Bluehill 4484 com AVE (Advanced Video Extensometer). A velocidade do ensaio foi de $3 \mathrm{~mm} / \mathrm{min}$ até $5 \%$ de deformação, acima deste valor a velocidade aumentou para $10 \mathrm{~mm} / \mathrm{min}$.

O módulo de elasticidade usado nos cálculos foi obtido utilizando a equação 2 válida no regime elástico com os dados do ensaio de tração da entrada.

Para o cálculo do coeficiente de encruamento foi usada a equação 1 , utilizando valores de tensão e deformação entre o LE e o LRT.

\footnotetext{
* Contribuição técnica ao $69^{\circ}$ Congresso Anual da ABM - Internacional e ao 14ํㅡㄹ ENEMET - Encontro Nacional de Estudantes de Engenharia Metalúrgica, de Materiais e de Minas,21 a 25 de julho de 2014, São Paulo, SP, Brasil.
} 


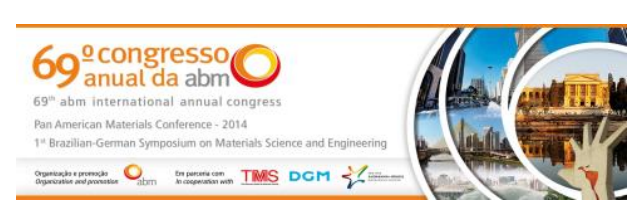

\subsection{Dureza Vickers}

O ensaio de dureza vickers foi escolhida por ser muito utilizada industrialmente por abranger uma longa faixa de dureza entra os materiais. A dureza vickers foi realizada no durômetro Herkert com carga de $50 \mathrm{kgf}$. As amostras foram lixadas a fim de obter uma superfície mais limpa e homogênea. Os resultados são as médias de 3 ensaios realizados em cada amostra.

\subsection{Metalografia}

$\mathrm{Na}$ metalografia as amostras passaram por procedimentos de corte, embutimento em baquelite, lixamento e polimento. Em particular o polimento foi feito primeiramente em alumina de $0,03 \mu \mathrm{m}$, sendo depois lavada com água destilada e em seguida polida com pasta de diamante de $6 \mu \mathrm{m}$ e $3 \mu \mathrm{m}$. Já para revelar a microestrutura foi feito o ataque colorido com reagente Klemm (100 ml de solução aquosa saturada de tiossulfato de sódio $+2 \mathrm{~g}$ de metabissulfito de potássio.) por imersão durante 2 minutos, lavando em água destilada e secada ao ar quente. $A$ microscopia ótica (MO) foi realizada no microscópio Olympus BX51M feita somente na DL a fim de observar o alongamento progressivo dos grãos.

\section{RESULTADOS E DISCUSSÃO}

\subsection{Ensaio de Tração}

A Figura 3apresenta o gráfico de tração realizado nas amostras na DL nas seis condições descritas na tabela 2.

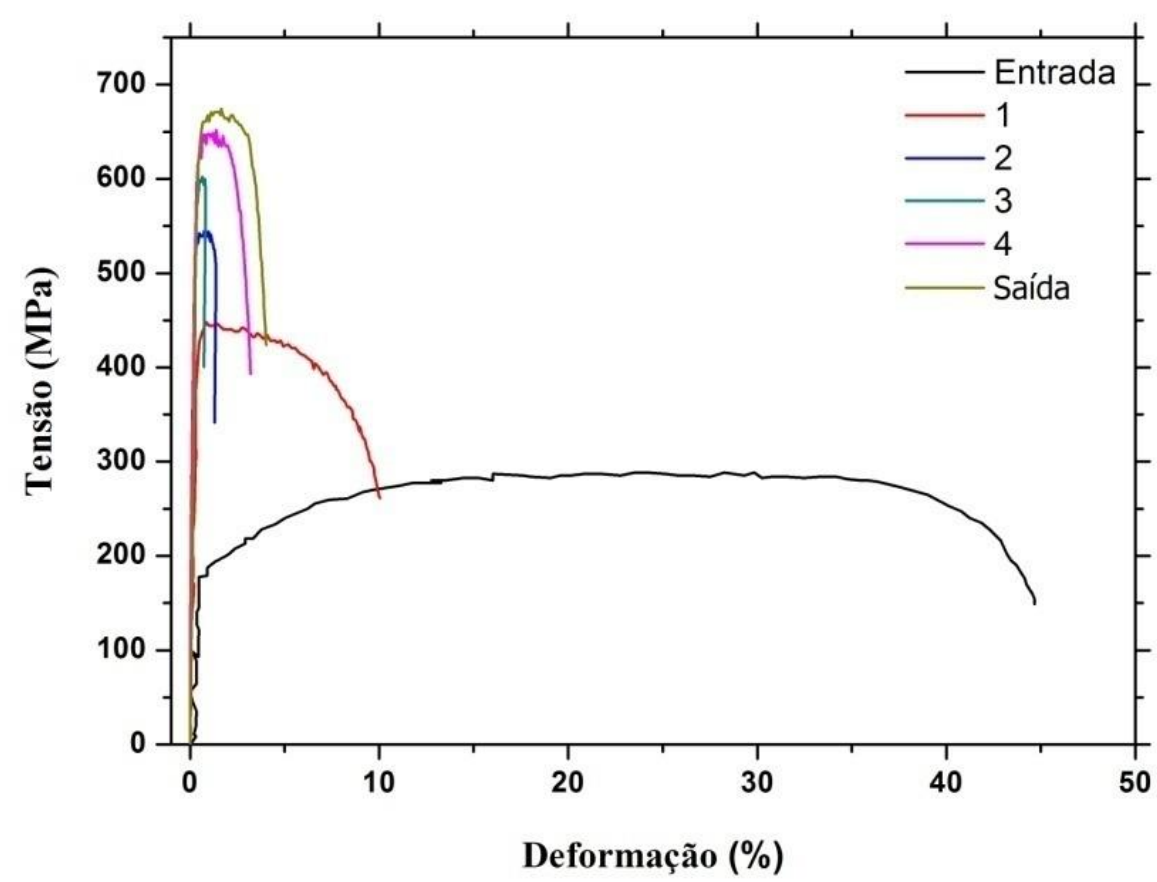

Figura 3. Curvas $\sigma \times \varepsilon$ convencional.

Já a Figura 5 tem-se as curvas obtidas nas amostras retiradas na DT.

\footnotetext{
* Contribuição técnica ao $69^{\circ}$ Congresso Anual da ABM - Internacional e ao 14ํㅡㄹ ENEMET - Encontro Nacional de Estudantes de Engenharia Metalúrgica, de Materiais e de Minas,21 a 25 de julho de 2014, São Paulo, SP, Brasil.
} 


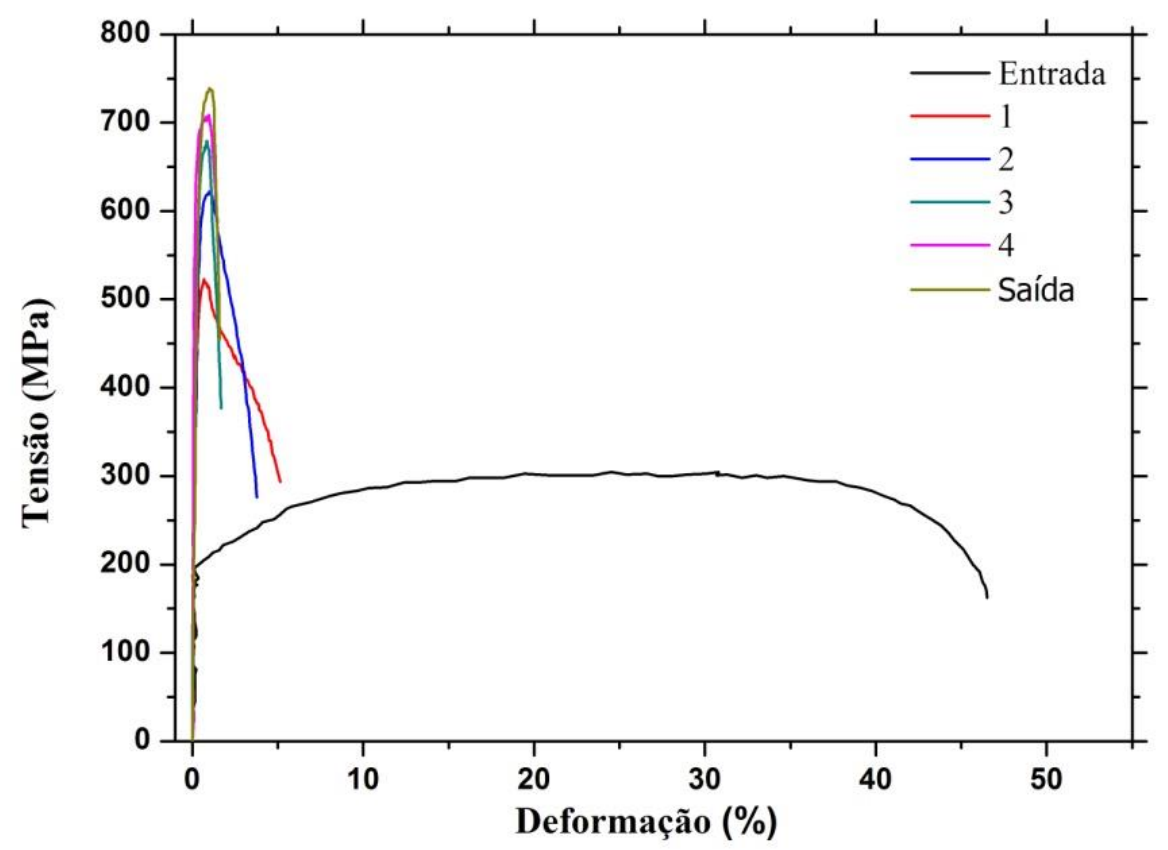

Figura 4. Curvas de $\sigma \times \varepsilon$ convencional.

Os gráficos da figura 3 e 4 apresentam as curvas de $\sigma \times \varepsilon$ antes e após laminação e entre os passes de laminação. Nota-se claramente o aumento do LE e do LRT da entrada até a amostra de saída do laminador e consequentemente a diminuição da ductilidade do material.

Nas tabelas 3 e 4 tem-se um resumo dos valores encontrados nos ensaios de tração na direção longitudinal e transversal de propriedades mecânicas bem como o valor do coeficiente de encruamento.

Tabela 3. Dados ensaio de tração DL

\begin{tabular}{ccccccc}
\hline DL & Espessura $(\mathrm{mm})$ & Área $\left(\mathrm{mm}^{2}\right)$ & $\begin{array}{c}\mathrm{LE} \\
(\mathrm{Mpa})\end{array}$ & $\begin{array}{c}\mathrm{LRT} \\
(\mathrm{Mpa})\end{array}$ & Alongamento \% & $\mathrm{n}$ \\
\hline Entrada & 3,85 & 47,86 & 177,00 & 288,00 & 46,10 & 0,21 \\
\hline 1 & 2,58 & 32,12 & 434,00 & 448,00 & 11,90 & 0,06 \\
\hline 2 & 1,53 & 18,77 & 537,00 & 542,00 & 1,20 & 0,02 \\
\hline 3 & 1,06 & 13,42 & 594,00 & 599,00 & 0,70 & 0,01 \\
\hline 4 & 0,75 & 9,25 & 631,00 & 643,00 & 3,20 & 0,03 \\
\hline Saída & 0,76 & 9,84 & 635,00 & 657,00 & 4,00 & 0,03
\end{tabular}

Tabela 4.Dados ensaio de tração DT

\begin{tabular}{ccccccc}
\hline DT & $\begin{array}{c}\text { Espessura } \\
(\mathrm{mm})\end{array}$ & Área $\left(\mathrm{mm}^{2}\right)$ & $\begin{array}{c}\mathrm{LE} \\
(\mathrm{Mpa})\end{array}$ & $\begin{array}{c}\text { LRT } \\
(\mathrm{Mpa})\end{array}$ & Alongamento \% & $\mathrm{n}$ \\
\hline Entrada & 3,75 & 48,34 & 198,00 & 303,00 & 48,50 & 0,19 \\
\hline 1 & 2,60 & 32,19 & 505,00 & 521,00 & 6,10 & 0,05 \\
\hline 2 & 1,62 & 20,75 & 597,00 & 621,00 & 3,90 & 0,03 \\
\hline 3 & 1,11 & 13,66 & 650,00 & 680,00 & 1,80 & 0,04 \\
\hline 4 & 0,78 & 9,88 & 670,00 & 708,00 & 2,30 & 0,01 \\
\hline Saída & 0,79 & 9,95 & 689,00 & 724,00 & 1,80 & 0,04
\end{tabular}

\footnotetext{
* Contribuição técnica ao 69ำ Congresso Anual da ABM - Internacional e ao 14ํㅡㄹ ENEMET - Encontro Nacional de Estudantes de Engenharia Metalúrgica, de Materiais e de Minas,21 a 25 de julho de 2014, São Paulo, SP, Brasil.
} 


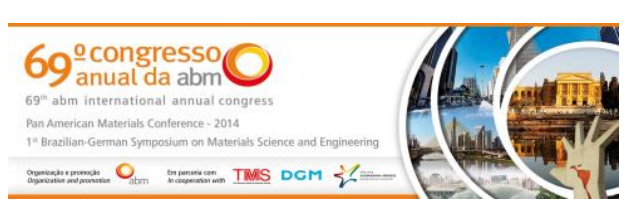

Por se tratar de um aço IF o valor do coeficiente de encruamento na entrada é alto (tabela 3 e 4) como descrito por Sampaio [4]. À medida que o material é deformado a frio este valor cai. Os valores de $n$ obtidos são um indicativo de que o material está encruando ao longo do processo.

Nas Figuras 5 e 6 tem-se a evolução das propriedades mecânicas como LE, LRT, redução de área e alongamento com o aumento da \% de redução a frio a cada cadeira de laminação.

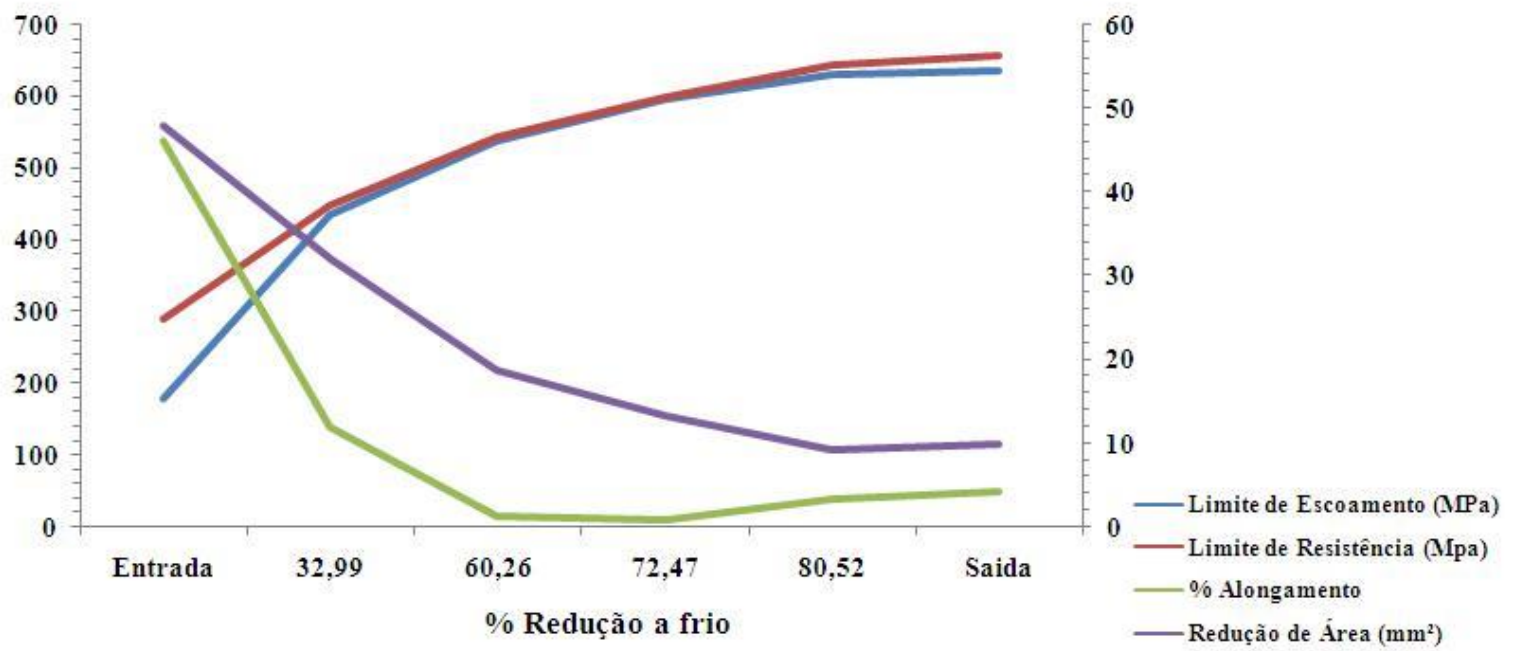

Figura 5. Comportamento das propriedades mecânicas com o aumento da deformação a frio na DL.

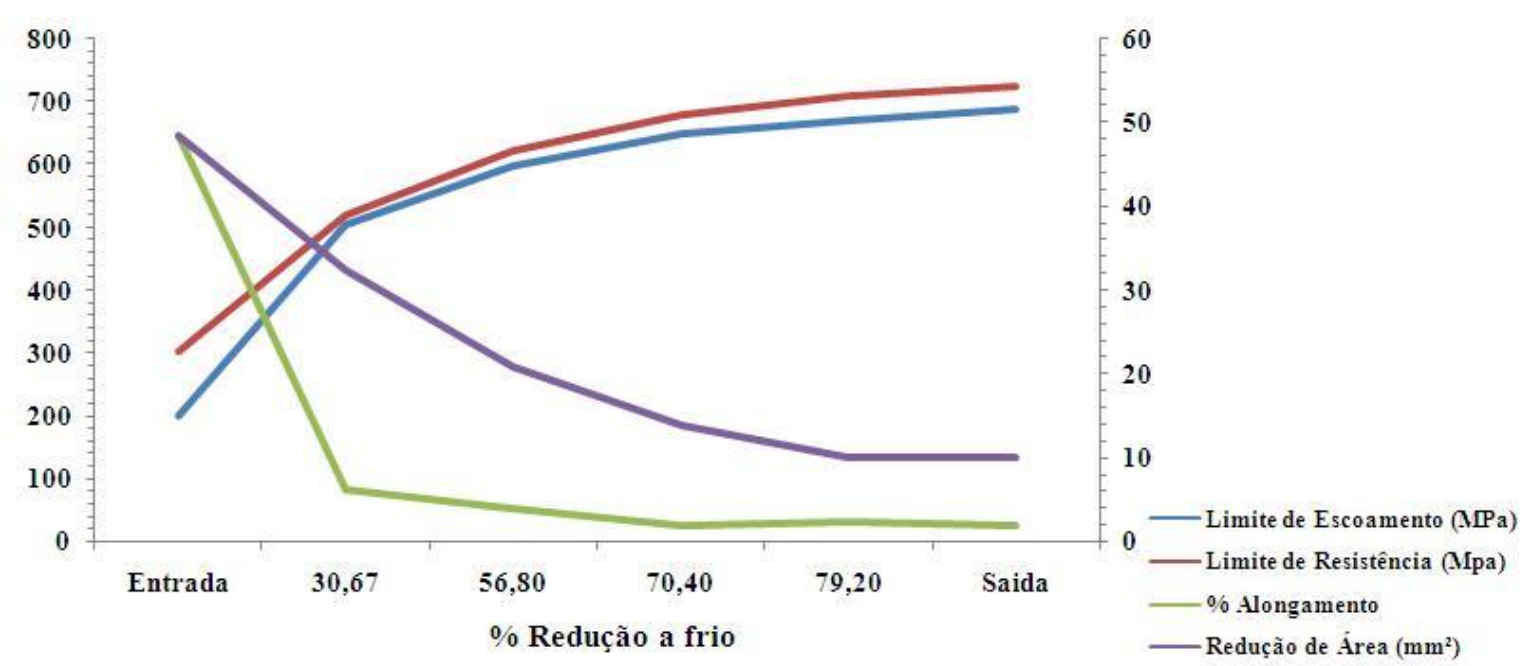

Figura 6. Comportamento das propriedades mecânicas com o aumento da deformação a frio DT.

Esta característica do efeito do trabalho a frio nas propriedades mecânicas em aços foi ilustrado por Silva [2]. O aumento da resistência mecânica do material leva consequentemente a diminuição da ductilidade do mesmo.

\footnotetext{
* Contribuição técnica ao 69ำ Congresso Anual da ABM - Internacional e ao 14ํㅡㄹ ENEMET - Encontro Nacional de Estudantes de Engenharia Metalúrgica, de Materiais e de Minas,21 a 25 de julho de 2014, São Paulo, SP, Brasil.
} 


\subsection{Ensaio de Dureza Vickers}

Os resultados do ensaio de dureza vickers encontram - se na Figura 7.

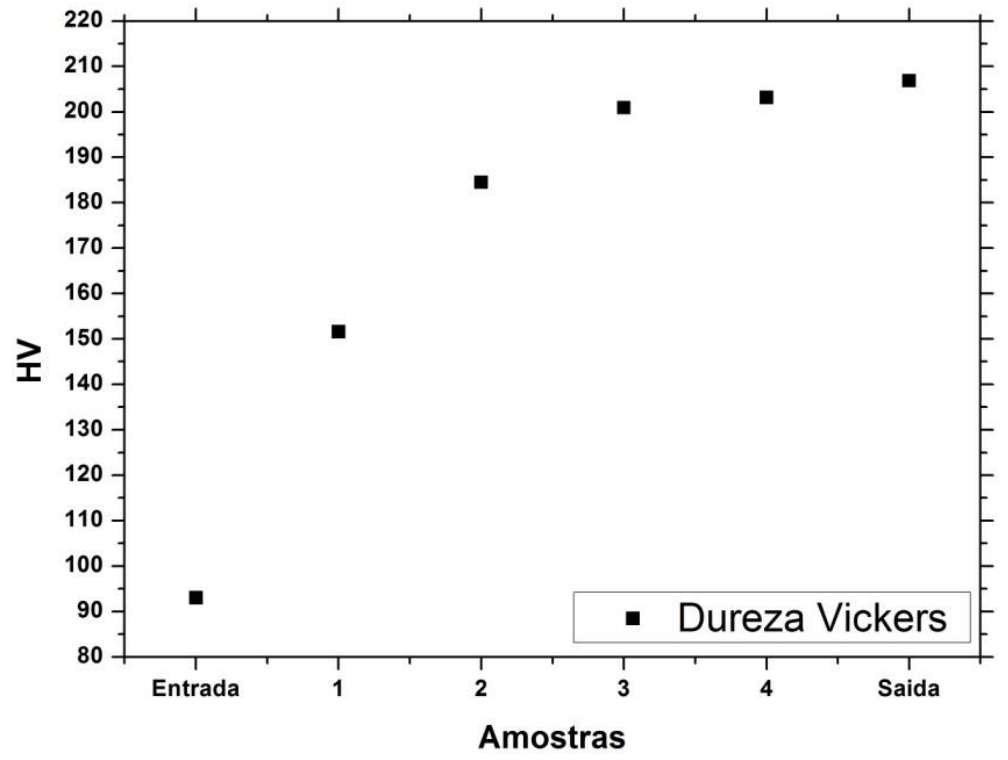

Figura 7. Dureza Vickers das amostras entre as cadeiras de laminação.

Os valores de dureza são crescentes como já era esperado devido ao endurecimento por deformação plástica.

\subsection{Metalografia}

As Figuras 8 a13 referem-se à microscopia ótica das amostras feitas após ataque. A Figura 8 apresenta os grãos equiaxiais recristalizados, antes do processo de laminação. Com a passagem pelo laminador, o material vai encruando progressivamente, o que é notório, quando se analisa as Figuras 9 a 13, que representa a microestrutura do material entre as cadeiras de laminação.

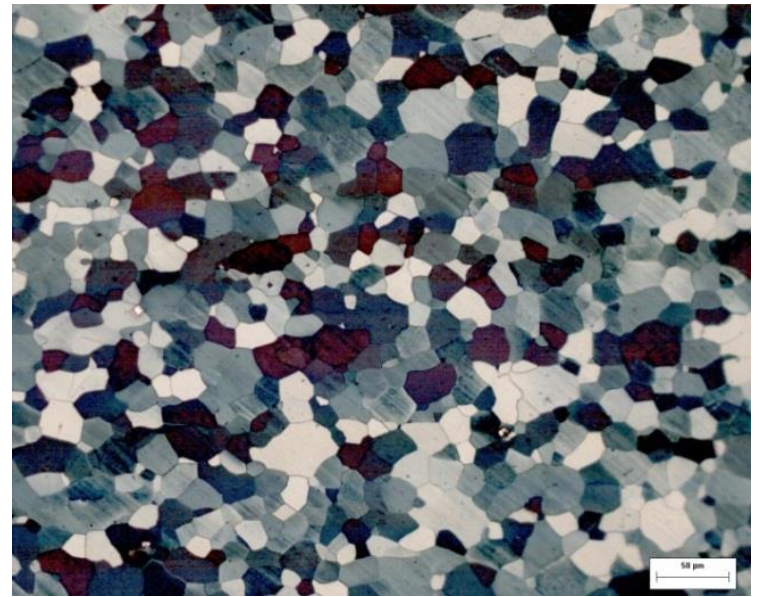

Figura 8. Entrada, MO aumento de 200x.

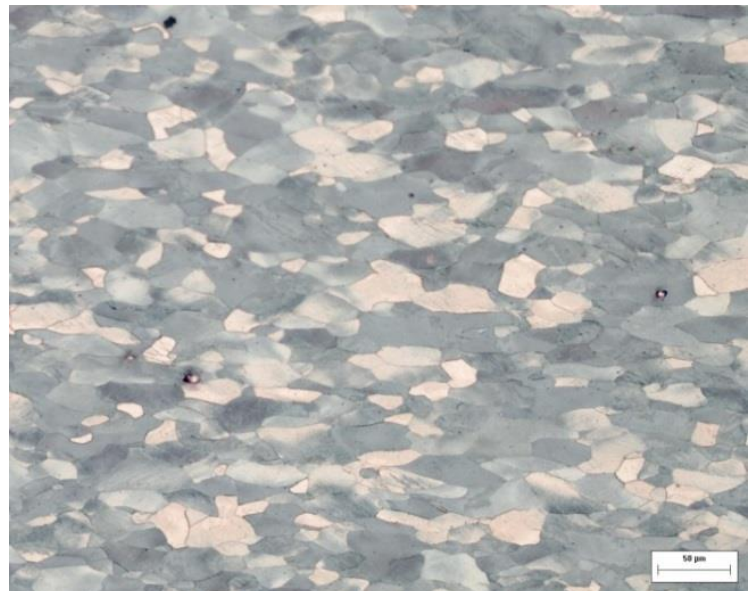

Figura 9. Amostra1, MO aumento de 200x.

\footnotetext{
* Contribuição técnica ao 69ำ Congresso Anual da ABM - Internacional e ao 14ํㅡㄹ ENEMET - Encontro Nacional de Estudantes de Engenharia Metalúrgica, de Materiais e de Minas,21 a 25 de julho de 2014, São Paulo, SP, Brasil.
} 


\section{CONCLUSÃo}

A evolução das propriedades mecânicas em laminação a frio, geralmente é estimada a partir de dados de entrada e saída do laminador. Neste trabalho foi calculado o limite de escoamento, limite de resistência à tração, alongamento, redução da área, dureza, entre outros, em amostras retiradas entre os passes de um laminador a frio industrial. Os dados obtidos neste trabalho podem servir como contribuição para a literatura tanto quanto para modelar o comportamento mecânico de aços IF no referido laminador, fornecendo resultados experimentais que dificilmente são obtidos.

\section{Agradecimentos}

A CSN pela oportunidade do estágio, em especial aos Engenheiros de Processo do LTF\#3 Hugo Shokychi Toshimitsu e Antônio Leonardo Santos pelo conhecimento técnico, a toda equipe de operação do LTF\# 3 no apoio para obtenção das amostras para realização deste trabalho e a Universidade Federal Fluminense responsável pela formação acadêmica.

\section{REFERÊNCIAS}

1 Machado MLP, Sobrinho VPFM, Arrivabene LF. Siderurgia para não siderurgistas. Vitória: ABM; 2003.

2 Silva ALVC, Mei PR. Aços e Ligas Especiais. São Paulo: Edgar Blücher, 3를. Ed, 2010, cap. 10, p. 581-583.

3 Curso Básico de Laminação a frio. Volta Redonda: CSN; 2013.

4 Sampaio AP, Zwirman NCS, Renó RT, Machado EA. Desenvolvimento de Aços Livres de Interticiais IF via Recozimento Contínuo e em Caixa. Volta Redonda: Seminário Tecnológico- CSN, 1998. 18 p.

5 Pinto MC, Klein LN, Castro LC, Alves AC. Desenvolvimento de aços interstitial free pela USIMINAS. Metalurgia e Materiais. São Paulo: ABM, 1992; 48(406): 327-333.

6 Rizzo EMS. Processos de Laminação dos aços: Uma Introdução. São Paulo: ABM;2007.

7 Padilha AF. Siciliano Júnior, F. Encruamento, Recristalização, Crescimento de Grão e Textura. 3 ${ }^{\underline{a}}$ ed. rev. São Paulo: ABM; 2005.

8 Barret CS. Structure of metals. First edition. New York: McGraw-Hill, 567p, 1952.

9 Humphreys FJ, Hatherly M. Recrystallization and related annealing phenomena. Second edition. Kidlington: Elsevier, 574p., 2004.

10 Souza SA. Ensaios Mecânicos de Materiais Metálicos. 5a Ed.rev. São Paulo: Edgard Blucher; 1982.

\footnotetext{
* Contribuição técnica ao $69^{\circ}$ Congresso Anual da ABM - Internacional e ao 14ํㅡㄹ ENEMET - Encontro Nacional de Estudantes de Engenharia Metalúrgica, de Materiais e de Minas,21 a 25 de julho de 2014, São Paulo, SP, Brasil.
} 